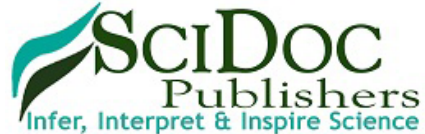

\section{Assessment of Variations in South Indian Dry Skulls Using Cranial Index: Craniometric Study}

Shebi $S^{1}$, M. Karthik Ganesh², M.P. Santhosh $\mathrm{Kumar}^{3^{*}}$

${ }^{1}$ Department of Oral and Maxillofacial Surgery, Saveetha Dental College and Hospital, Saveetha University, India.

${ }^{2}$ Assistant Professor, Department of Anatomy, Saveetha Dental College and Hospital, Saveetha University, India.

${ }^{3}$ Reader, Department of Oral and Maxillofacial Surgery, Saveetha Dental College and Hospital, Saveetha Institute of Medical and Technical Sciences (SIMATS), Saveetha University 162, Poonamallee High Road, Velappanchavadi, Chennai 600077 Tamil Nadu, India.

\title{
Abstract
}

Cranial index is the ratio of maximum width of the head divided by its maximum length multiplied by 100 . Maximum cranial length is from the summit of glabella to the furthest occipital point; the maximum cranial breadth is from greater breadth at right perpendicular to median plane and the cranial height is from basion to bregma. The cranial index is used in anthropology to characterize the shape of the skull in the horizontal plane. Low values reflect a relatively long and narrow skull.Various systemsexist to divide crania into longheaded(dolichocephalic), medium headed(mesocephalic) and roundheaded(brachycephalic). The most widespread system classifies the skull with a cranial index greater than 80 percent as brachycephalic, less than 75 percent as dolichocephalic and between 75 and 80 percent as mesocephalic. Index is used as a means of distinguishing anthropology racial types from skeleton. This study analyses and classifies the South Indian Dry Skulls Using Cranial Index. According to our study, majority of the skull types were dolichocranic and few were mesocranic skull types. The data can be useful for forensic medicine experts, anatomist, anthropologist, oral surgeons and for clinical and research purposes.

Keywords: Cranial Length; Cranial Breadth; Cranial Index; Dry Skull; Forensic Medicine; Head Shape; Identification.

\section{Introduction}

Much attention has been given in the variations of the shape and size of the human skull and efforts have been made to associate these variations to characterize different races [1]. Careful, skilled examination of body remnants can put forward valuable information that may help in the identification of a person [2]. The skull is a part of skeleton that is very suitable for examinations with regard to identification. The skull without the mandible is regarded as cranium [3]. Establishment of factors such as sex, race, age and stature from the available human remains may contribute towards an approximation of identity and the consequent report accepted as evidence in court of law subject to testifying itsveracity. Cephalic index formed one of the frequently employed parameters in physical anthropology to identify the races [4]. It is a matter of common experience that in dealing with crania of different racial types, an impression of racial affinity and differences is seen.
Skeletal metric and non-metric variables are widely used for such studies $[5,6]$.

Measurements play an important role in skeletal morphology. Cranial measurements have been used to describe individuals and to correlate various ethnic and racial groups. These measurements have also shown the shape and size variations in different racial groups [7]. Cranial Index (CI) and Cephalic Index (in living) is useful anthropologically to find out racial and sexual differences. It is important in anthropometric indices, in diagnostic knowledge between the patient and normal populations and in the medicolegal cases of Forensic Medicine. The Craniometric results can also be of great assistance while evaluating patients in various fields of medicine like Medical Imaging, Paediatrics, Craniofacial Surgery and also for studying growth trends in various castes and races within a defined geographic zone [8]. The observations and findings of this study will provide platform for similar extended

*Corresponding Author

M.P. Santhosh Kumar,

Reader, Department of Oral and Maxillofacial Surgery, Saveetha Dental College and Hospital, Saveetha Institute of Medical and Technical Sciences (SIMATS), Saveetha University 162, Poonamallee High Road, Velappanchavadi, Chennai 600077 Tamil Nadu, India.

Tel: 9994892022

Email ID: santhoshsurgeon@gmail.com

Received: April 09, 2021

Accepted: May 02, 2021

Published: May 10, 202

Citation: Shebi S, M. Karthik Ganesh, M.P. Santhosh Kumar. Assessment of Variations in South Indian Dry Skulls Using Cranial Index: Craniometric Study. Int J Dentistry Oral Sci. 2021;08(5):2420-2422. doi: http://dx.doi.org/10.19070/2377-8075-21000476

Copyright: M.P. Santhosh Kumar ${ }^{\circ}$ 2021. This is an open-access article distributed under the terms of the Creative Commons Attribution License, which permits unrestricted use, distribution and reproduction in any medium, provided the original author and source are credited. 
Craniometric studies based on various communities, castes and races of particular geographic zones.

On the basis of cephalic/cranial index head shapes were grouped into four international categories, which includes, Dolicocephalic (Greek Kephale - head and dolikhos - long and thin), Brachicephalic (short and broad), Mesocephalic (intermediate length and width) and Hyperbrachicephalic (very short and broad) [7]. Australian aborigines and native southern Africans are Dolicocephalic, Europeans and the Chinese skulls are Mesocephalic and Mongolians and the Andaman Islanders have Brachicephalic skulls. Comparison between cephalic indices and the head shapes with race, age and sex is important. They are valuable for treatment monitoring and prediction of orthodontic treatment; in plastic and reconstructive surgeries concerned with craniofacial deformities [8].

\section{Material and Methods}

In the present study, a total of 20 dry human fetal skulls of unknown sex and without any gross abnormality were collected from the Department of Anatomy, Saveetha Dental College, Chennai and from Madras Medical College, Chennai and were evaluated. All skulls were serially numbered from 1 to 20.With the help of Vernier Caliper and Scale, the following measurements were taken (Figure 1 and Figure 2).

- Maximum Cranial Length (A) = Summit of glabella to the furthest occipital point

- Maximum Cranial Breadth (B) = Greater breadth at right angle to median plane

- Cranial Index $(\mathrm{CI})=\mathrm{B} / \mathrm{A} \times 100$

The results obtained were analyzed, tabulated and classified.

\section{Result}

In our study, among the various types of head shapes, the doli- chocephalic type was the highest and mesocephalic was the lowest. The mean cephalic index was 71.05. Pearson's correlation was used to calculate the significance of correlation between cephalic index and cranial volume; and between cephalic index and cranial measurements.

The skulls with CI up to 74.9 or below 75.0 were classified as Dolichocranic (Long headed). Skulls with CI between 75.0 to 79.9 were considered as Mesocranic (Medium headed) and those with CI greater than 80.0 or between 80.0 to 84.9 were classified as Brachycranic (Round headed) [Table 1]. The Maximum Cranial Length ranged from 16.5 to 20.0 with Mean value of 17.92. The Maximum Cranial Breadth ranged from 11.5 to 14.0 with Mean value of 12.72. Cranial Index (CI) ranged between 63.88 and 79.41 with average value of 71.05 [Table 2]. When all the calculated CI were listed, Dolichocranic skulls accounted to the maximum of $84 \%(\mathrm{CI}=70.10)$, Mesocranic skull accounted for $16 \%(\mathrm{CI}=76.39)$ and there were no Brachycranic skulls [Table 3].

\section{Discussion}

In the present study, the majority of the skulls belonged to the commonest head shape Dolichocranic (short headed) with mean CI of 70.10 and few were of Mesocranic (medium headed) category with mean CI of 76.39.Variations in cephalic indices between and within populations have been attributed to a complex interaction between genetic and environmental factors. The mean cranial index in different ethnic groups varies significantly in different geographic zones [8]. The genetic factors also influence the cranial shape.Indirect estimation of the cranial volume has been attempted in several studies using dimension of some parts of the skull like Roentgenological length [9]; area of the foramen magnum [10, 11]; Calvarialdis placement volume [12]; product of median surface area of the skull and the biparietal diameter [13, 14]. It may be possible to derive a conclusion for calculating cranial volume or cranial indices using head length and breadth.This may be of use in reconstruction of the head shape and size from remains of an individual where only a fragment of the head or

Table 1. Types of Head Shape.

\begin{tabular}{|c|c|}
\hline Head Shape & Cranial Index Range \\
\hline Dolichocranic & $70.0-74.9$ \\
\hline Mesocranic & $75.0-79.9$ \\
\hline Brachycranic & $80.0-84.9$ \\
\hline
\end{tabular}

Table 2. Parameters of Cranial Index.

\begin{tabular}{|c|c|c|}
\hline PARAMETER (cm) & RANGE & MEAN \\
\hline Maximum Cranial Length (A) & $16.5-20.0$ & 17.92 \\
\hline Maximum Cranial Breadth (B) & $11.5-14.0$ & 12.72 \\
\hline Cranial Index (CI) & $63.88-79.41$ & 71.05 \\
\hline
\end{tabular}

Table 3. Categorization of skulls based on Cranial Index.

\begin{tabular}{|c|c|c|c|}
\hline Head Shape & Mean & $\mathbf{n}=\mathbf{5 0}$ & $\mathbf{\%}$ \\
\hline Dolichocranic & 70.1 & 42 & $84 \%$ \\
\hline Mesocranic & 76.39 & 8 & $16 \%$ \\
\hline Brachycranic & Nil & Nil & Nil \\
\hline
\end{tabular}


the skull with maximum head breadth is available [15]. With a rich case bank, we have published extensive studies on craniometric analysis in the past decade [16-22]. However further studies using larger samples of subjects of different ethnic groups may establish the usefulness of this method of deriving cranial volume and Cranial Indices.

\section{Conclusion}

Variation in the Cranial Index predicts some utility in distinguishing skulls from different geographic regions. In the present study majority of the skull types were dolichocranic and few were mesocranic skull types. The data can be useful for forensic medicine experts, anatomist, anthropologist, oral surgeons and for clinical and research purposes. The observations and result of this study may provide platform for similar Craniometric studies based on various communities, castes and races of particular geographic regions.

\section{References}

[1]. Hamilton WJ. Textbook of human anatomy. Springer; 1982 Jun 18.

[2]. Kaithackal JB. STUDY ON NORTHERN AND SOUTHERN INDIA VARIATIONS OF HUMAN SKULL-A SECONDARY RESEARCH. J Evid Based Med Healthc. 2016;3:5491-4.

[3]. Williams PL. Warwick R. Gray's anatomy. Edinburgh: Churchill Livingstone. 1980

[4]. Raveendranath V, Manjunath K. An anthropometric study of correlation between cephalic index, cranial volume and cranial measurements in Indian cadavers. Indian Science Abstracts. 2010 Sep;15(2):55-8.

[5]. Finnegan M, Cooprider K. Empirical comparison of distance equations using discrete traits. Am J Phys Anthropol. 1978 Jul;49(1):39-46. Pubmed PMID: 677296

[6]. Tildesley ML. A first study of the Burmese skull. Biometrika. 1921 Jul $1 ; 13(2 / 3): 176-262$.

[7]. Williams P, Dyson M, Dussak JE. Bannister. LH; Berry, MM; Collins, P. \&Fergson, MWJ Gray's Anatomy. Skeletal system. 38th Ed. Elbs with Churchill Livingston. London. 1995:607-12.
[8]. Kumar A, Nagar M. Morphometric estimation of cephalic index in north Indian population: craniometrics study. International Journal of Science and Research. 2015;4(4):1976-82.

[9]. Lobo SW, Chandrasekhar TS, Kumar S. Cephalic index of Gurung community of Nepal--an anthropometric study. Kathmandu Univ Med J (KUMJ). 2005 Jul-Sep;3(3):263-5. Pubmed PMID: 18650589.

[10]. MACKINNON IL. The relation of the capacity of the human skull to its roentgenological length. Am J Roentgenol Radium Ther Nucl Med. 1955 Dec;74(6):1026-9. Pubmed PMID: 13268737.

[11]. Ashton EH, Spence TF. Age changes in the cranial capacity and foramen magnum of hominoids. InProceedings of the Zoological Society of London 1958 Mar (Vol. 130, No. 2, pp. 169-181). Oxford, UK: Blackwell Publishing Ltd.

[12]. Kumar A, Dave M, Anwar S. Morphometric evaluation of foramen magnum in dry human skulls. Int J Anat Res. 2015;3(2):1015-23.

[13]. Venkatesan B, Cooper MM. Calvarial displacement volume as a guide to cranial capacity.(Abstract) 23rd annual conference of Anatomical Society of India, at Banaras Hindu University, Banaras. Journal of Anatomical Society of India. 1975;24(1):40.

[14]. Müke R, Homann G, Waiter H. Investigations for skull volume determination. InRöFo progress in the field of X-rays and imaging methods. 1976 Sep;125(9): 219-225.

[15]. Logan CJ, Palmstrom CR. Can endocranial volume be estimated accurately from external skull measurements in great-tailed grackles (Quiscalus mexicanus)? PeerJ. 2015 Jun 11;3:e1000. Pubmed PMID: 26082858.

[16]. Malay KK, Duraisamy R, Brundha MP, Kumar MP. Awareness regarding anemia among 1 st year dental undergraduate students. Drug Invention Today. 2018 Aug $1 ; 10(8)$.

[17]. Kumar MS. Knowledge, attitude and practices towards oral health among law students in Chennai. Journal of Pharmaceutical Sciences and Research. 2016 Jul 1;8(7):650.

[18]. Kumar MP. Dental management of patients on antiplatelet therapy: Literature update. Asian J Pharm Clin Res. 2016;9(3):26-31.

[19]. Kumar S. Newer delivery systems for local anesthesia in dentistry. J Pharm Sci Res. 2015;7(5):252-5.

[20]. Ahamed A, Kumar MS. Knowledge, attitude and perceived confidence in handling medical emergencies among dental students. Journal of Pharmaceutical Sciences and Research. 2016 Jul 1;8(7):645.

[21]. Kumar S. Knowledge, attitude and practices of dental students toward dental management of patients on antiplatelet therapy. Asian J Pharm Clin Res. 2016;9(30):270-6.

[22]. Gayathri MM. Knowledge, Awareness and Attitude among dental students about hepatitis B infection. Journal of Pharmaceutical Sciences and Research. 2016 Mar 1;8(3):168. 